\title{
Demand management by active consumers in intelligent electric power systems
}

\author{
Evgeny Tretyakov ${ }^{1, *}$ \\ ${ }^{1}$ Omsk State Transport University, Marksa, 35, Omsk, 644046, Russia
}

\begin{abstract}
The approaches to demand management by active consumers through forming a given schedule of power consumption in the required period of time based on the solution of the optimization problem in the form of maximizing the power of connected controlled electric receivers of various types are presented. The model of demand management by active consumers is justified, taking into account the following factors: load sensitivity for connecting a transformer substation to a change in consumer load; load priority; consistent load reduction levels with flexible performance and power control; permissible set of electric receivers in accordance with the technological process, network schedule, other logical conditions corresponding to adjacency lists. An algorithm has been developed for limiting power on the part of active consumers based on the widespread use of digital data processing technologies, modern technical means of measurement, control and switching of end consumers in real time. The presented research results indicate the validity of the demand management method by active consumers in the normal mode of intelligent electric power systems and the possibility of its practical implementation in an industrial enterprise with reference to the technological process.
\end{abstract}

\section{Introduction}

Many authors consider demand management of active consumers based on the economic interests of electricity generation, distribution and consumption, developing various market models for their interaction $[1,2]$. In the Russian Federation, in accordance with Decree of the Government of the Russian Federation of July 20, 2016 No. 699 "On Amending the Rules for the Wholesale Market of Electric Energy and Power", a price-dependent decrease in consumption by large consumers of the wholesale market of electricity and capacity, as well as consumers of the retail electricity market with the participation of organizationsaggregators.

To ensure the total volume of price-dependent reduction in power consumption, industrial and other comparable enterprises should have appropriate approaches to the flexible change of technological processes without harming their activities.

A number of works $[4,5]$ propose a universal model for demand management of active consumers based on aggregate modeling of the possible and ultimate duration of disconnection for all sets of connections at the time of the start of disconnection. Moreover,

*Corresponding author: eugentr@mail.ru 
disconnection of consumer connections is considered from a probabilistic point of view in the form of discrete random variables. The practical implementation of this approach seems somewhat difficult in real time.

In the future, the methods of probabilistic management of active consumers will be superseded by approaches based on full observability and real-time controllability within the framework of the concepts of the industrial Internet of things and energy [6]. In this case, the connection of such consumers to the electric networks should be fully controlled with the help of switching devices and (or) adjustable interface devices and equipped with an automated system for metering electricity, power, etc., and the interaction between active consumers and participants in the electricity market should be performed in a single software environment.

Production and technological processes of active consumers should also be controlled (managemented) by an automated system. Digitalization of production and technological processes of enterprises and organizations is the basis for obtaining the necessary information about retrospective, current and prediction data from all electric receivies and their relationship, both to increase the efficiency of the production process and for the purpose of managing active consumers in real time.

This study is related to the development of possible approaches to demand management by active consumers in intelligent electric power systems.

\section{Materials and methods}

Obviously, the main motive of an active consumer to participate in balancing the power of the electric power system is the material benefit in the form of a discount to the tariff for consumed electricity and (or) power, as well as possible other favorable conditions from a guaranteeing electricity supplier, for example, an increase in contractual capacity, elimination of consumption restrictions subject to categorization and so on.

For an active consumer, the main task is to change the power consumption for connections by a certain amount or within the required limits from some point in time to a given duration without negative consequences and even less harm to oneself.

From the point of view of a possible change in power consumption, all electrical receivies of consumers can be conditionally divided into groups:

- non-disconnectable (in normal and emergency mode);

- non-disconnected (in normal mode);

- disconnected;

- with the possibility of reducing the consumed active power within $\Delta P_{\min }-\Delta P_{\max }$ (in normal mode);

- with the possibility of reducing the consumed active power within $\Delta P_{\min }^{{ }_{\text {min }}}-\Delta P_{\text {max }}{ }_{\text {(in }}$ (in emergency mode).

In some cases, control of part of the loads can be transferred to the system operator (aggregator).

The task of forming an optimal schedule of electricity consumption by household and industrial consumers is considered literally in many works, i.e. as the sum of individual loads, taking into account the duration of connection, on condition that the minimum cost of electricity consumption [7]. In this case, the interconnection of electric receivers by functional feature is not taken into account, which usually corresponds to household consumers. In [8-10], a model of an active consumer is presented with minimum cost electricity consumption based on the assignment of planned load schedules with their own profitability coefficients and taking into account changes in the cost of electricity during the billing period if there is own generation. Many works are also associated with determining the optimal electric consumption schedule for the minimum cost for MicroGrid [11-12], for 
the group of heterogeneous consumers in general [13], as well as for minimizing the shape factor of the load graph [14].

To manage the demand of active consumers of electric power systems for balancing capacity in normal and emergency mode, it is necessary to be guided not only by possible cost-based incentive mechanisms for reducing electricity demand, which are probabilistic in nature, but also by contractual obligations of the system operator (aggregator) and the consumer.

In the normal mode of operation of electric power systems, planning of power consumption by consumers at peak hours is carried out in advance and can be reduced, for example, due to:

- revising and changing the network schedule of technological and production processes;

- review and implementation of a shift in the time of operation of electric receivers with a variable load, depending on the volume of work performed;

- change of operating modes of electric receivers with flexible regulation of productivity and power for the period of peak load (electrothermal, refrigeration, pumping, ventilation equipment, etc.);

- commissioning of generating capacities and (or) electric energy storage systems, etc.

In this study, we consider possible approaches to limiting the power of an active industrial consumer to a given value for the implementation of contractual relations with a system operator (aggregator). Obviously, an active consumer takes part in a power reduction program, having the technical ability to balance its load at the request of a system operator (aggregator).

Electric receivers (ER) of various groups of technological processes, installations and administrative buildings are geographically distributed between different power sources and cannot be controlled by a single connection, feeder, line, complete transformer substation and often transformer substation. In Fig. 1 shows a typical circuit diagram of a power supply for consumers, for example, an industrial enterprise.

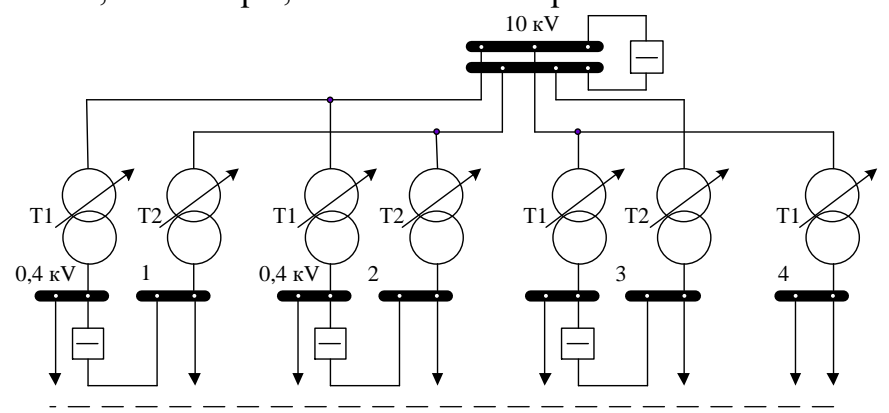

Fig. 1. Circuit diagram of the power supply to consumers.

The proposed approach to limiting power on the side of active consumers can be implemented in a hardware-software complex based on the widespread use of digital data processing technologies and modern technical means of measurement, control and switching in distribution electric networks. In particular, all connections with large electric receivers and technological installations involved in disconnecting / reducing active power must be equipped with electrical measuring devices and controlled switching devices. Technological installations with flexible regulation of productivity and power (electrothermal, refrigeration, pumping, ventilation equipment, etc.) must have communication channels with the hardware-software complex.

The initial data for controlling the power limitation are measured signals of power, connecting / disconnecting, technological parameters from electric receivers and a database 
that describes the permissible modes, limitations, technological communications of electrical equipment, etc.

The connections of various electric receivers is advisable to describe the matrix or adjacency lists based on graph theory [15]:

- adjacency lists for describing the connections of electric receivers included in a technological operation, process or electrical installation;

- adjacency lists for describing the electrical connections of electric receivers with supply centers;

- adjacency lists for describing the connections between technological operations, processes or electrical installations.

In the same way, adjacency lists are formed to describe the electrical connections of electric receivers with power centers, as well as between technological operations, processes or electrical installations.

Based on the built-in structure of electric receivers (according to adjacency lists) with an indication of electrical, technological and other connections, a statistical analysis of data in real time (with a sampling frequency several times per second) is performed, including operating time (forming a real network diagram of technological processes), electricity consumption and capacities for technological operations, types of electric receivers, directions of use, connections, etc.

At the next stage, until the power is limited, the predicted power consumption is checked for compliance with the plan. As a plan, we consider the total and corresponding individual load schedules that meet the specified restrictions on power consumption in a specific period of time of a given duration, received in advance (usually per day) from the system operator (aggregator):

$$
P^{t} \cdot k_{t} \leq P_{o p}^{t}, P_{o p}^{t}=f(t), t \in\left(t_{1}-t_{2}\right)
$$

$P^{t}-$ total predicted power consumption at time $t ; k_{t}$ - safety factor; $P_{o p}^{t}-$ the reference plan corresponding to the given power limitations in the time period $t_{1}-t_{2}$.

Prediction of the load schedule for the day ahead is carried out with a sampling rate corresponding to the frequency of receiving data from information-measuring systems (as a rule, several times per second). As you approach a time period with a given power limit, the accuracy of the forecast increases. The safety factor takes into account the random nature of the load that is not involved in demand management, as well as the error in prediction and power management methods.

In case of failure to fulfill condition (1), automatic operation of electric receivers, load schedule at the time of implementation of the restriction and power plan (according to the prediction) is automatically adjusted: optimization of the operation modes of the regulated and disconnected loads.

The graph of the active power load for the purposes under consideration can be represented as the sum of monitored (managed) individual schedules equipped with an individual metering and switching system, and uncontrolled (random stationary):

$$
P^{t}=\sum_{i=1}^{n} p_{1 i}^{t}+\sum_{i=1}^{n} p_{2 i}^{t}+\ldots+\sum_{i=1}^{n} p_{m i}^{t}+m_{P}+\Phi(\beta) \sigma_{P},
$$

where $\sum_{i=1}^{n} p_{1 i}-$ controlled electric receivers of the technological process, operations; $\sum_{i=1}^{n} p_{2 i}$ - controlled electric receivers with flexible regulation of performance and power; $\sum_{i=1}^{n} p_{m i}-$ for example, controlled semi-permanent electric receivers, including non-disconnectable ones; $m_{P}-$ mathematical expectation of uncontrolled random stationary processes of load 
change; $\Phi(\beta)$ - the function inverse to the probability integral $\beta$ of the distribution law (for example, for the normal distribution law $\Phi(0,95)=1,64) ; \sigma_{P}$ - standard deviation of the power of an uncontrolled load.

The statistical characteristics of uncontrolled load curves of active power can be calculated based on the processing of retrospective and prediction data obtained by subtracting from the general load schedule for connecting controlled load schedules of individual electric receivers according to the information of measuring systems.

In general, the target demand function for connecting the transformer substation with active (controlled) consumers under given power restrictions by a system operator (aggregator) over a period of time $t \in\left(t_{1}-t_{2}\right)$ can be written as maximizing the power of connected active consumers: disconnected and with flexible regulation of performance and power at time $t$ :

with restrictions:

$$
\begin{gathered}
F=\sum_{i=1}^{n} p_{1 i} \cdot v_{i} \cdot \Delta \omega_{i} \cdot x_{i}+\sum_{k=1}^{m} p_{2 k} \cdot v_{k} \cdot \Delta \omega_{k} \cdot y_{k} \rightarrow \max \\
x_{i}=0,1(i) \in Z \\
y_{k \min }, \quad y_{k \max } \in(0-1)
\end{gathered}
$$

$$
\begin{aligned}
& P^{t} \cdot k_{t} \leq P_{o p}^{t}, t \in\left(t_{1}-t_{2}\right) ; \\
& \sum_{i=1}^{n} x_{i}=a ; y_{k \min } \leq y_{k}<y_{k \max } ; \\
& \Delta P_{k \min } \leq p_{2 k} \cdot y_{k} \leq \Delta P_{k \max } ; \\
& p_{1 i}, x_{i} \in B ; G,
\end{aligned}
$$

where $v_{i}, v_{k}$ - priority of the load, determined by ranking consumers according to the importance of the load (in the range $0-1$ ); $\Delta \omega_{i}, \Delta \omega_{k}-$ sensitivity of the load on the connection of the transformer substation to the change in the load of the consumer (in the range $0-1) ; x_{i}$ - binary variable $(0$ or 1$) ; y_{k}-$ continuous variable - coefficient of change in load power from minimum to maximum (in the range $0-1$ ); $a$ - integer that determines the status of disconnected electric receivers; $n, m$ - number of electric receivers with the ability to turn them off and with flexible power control, respectively; $\Delta P_{k \min }, \Delta P_{k \max }$ - harmonized levels of load reduction with flexible regulation of performance and power; $B$ - valid set of electric receivers in accordance with the technological process, network schedule, other logical conditions corresponding to adjacency lists; $G$ - adjacency list describing the connections of electric receivers included in a technological operation, process or electrical installation.

Based on the results of solving the mixed integer programming problem (3), a suitable set of electric receivers is determined from the acceptable ones, as well as the reduction amount of electric receiver power with flexible performance control, taking into account the given restrictions, to ensure that the total load schedule for connecting to a given value matches.

\section{Results}

Consider the implementation of the presented approaches to demand management by an active consumer by forming a predetermined schedule of power consumption in the required period of time using the example of an electric locomotive repair plant. In Fig. 3 
shows the connections of controlled (active) electric receivers included in a technological operation, process or electrical installation (using the example of one workshop).

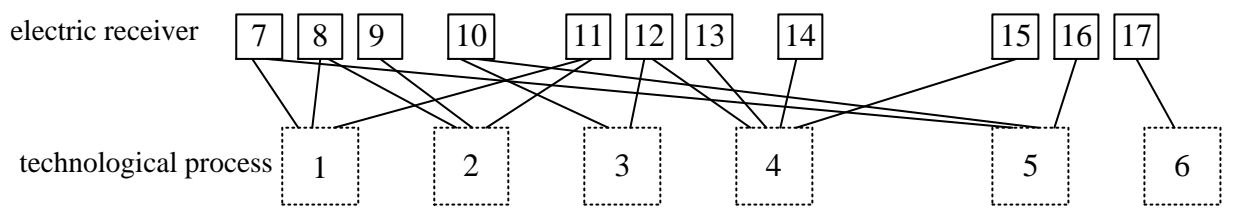

Fig. 2. Connections of electric receivers included in a technological operation, process or electrical installation (direction of use).

The adjacency list $\mathrm{G}$ for the description of the connections of electric receivers included in the technological operation, process or electrical installation has the form (for example, for Fig. 2):

\begin{tabular}{|c|c|c|c|c|c|c|c|}
\hline $1 \rightarrow$ & $7 \rightarrow$ & $8 \rightarrow$ & 11; & $7 \rightarrow$ & $1 \rightarrow$ & 5 & $13 \rightarrow$ \\
\hline $2 \rightarrow$ & $8 \rightarrow$ & $9 \rightarrow$ & 11; & $8 \rightarrow$ & $1 \rightarrow$ & $2 ;$ & $14 \rightarrow$ \\
\hline $3 \rightarrow$ & $10 \rightarrow$ & 12 & & $9 \rightarrow$ & 2 & & $15 \rightarrow$ \\
\hline $4 \rightarrow$ & $12 \rightarrow$ & $13 \rightarrow$ & 14 & $10 \rightarrow$ & $3 \rightarrow$ & 5 & $16 \rightarrow$ \\
\hline $5 \rightarrow$ & $7 \rightarrow$ & $10 \rightarrow$ & 16; & $11 \rightarrow$ & $1 \rightarrow$ & $2 ;$ & $17 \rightarrow$ \\
\hline $6 \rightarrow$ & 17; & & & $12 \rightarrow$ & $3 \rightarrow$ & 4 & \\
\hline
\end{tabular}

An automated demand management system performs real-time processing and statistical analysis of measured and input data. Measurement of electrical and other controlled parameters of electric receivers allows to have extensive information about the progress of the technological process, its compliance with the network schedule, including operating time and electricity and power consumption for technological operations, types of electric receivers, etc.

Based on modern intelligent prediction methods, a load schedule is generated within the next day, when the power limit of active consumers is set, to assess its compliance with the planned power consumption. At the same time, retrospective data on load schedules, the indicated adjacency lists, the network schedule of technological operations, ambient temperature, production interlocks, restrictions, logical conditions and other data that provide increased prediction accuracy are taken into account.

The optimization problem of mixed integer programming (10) was solved by the branch-and-bound method using software for each time point taken into account, taking into account the data presented in Table 1.

Table 1. Basic data

\begin{tabular}{|l|c|c|c|c|c|c|c|c|c|c|c|}
\hline \multirow{2}{*}{ Indicator } & \multicolumn{10}{|c|}{ Value for electric recievers } \\
\cline { 2 - 15 } & 1 & 2 & 3 & 4 & 5 & 6 & 7 & 8 & 9 & $\ldots$. & 307 \\
\hline$v_{i}$ & 1 & - & 0.3 & 0.95 & 1 & 0.6 & 0.7 & - & - & $\cdots$ & 0.8 \\
\hline$v_{k}$ & - & 0.9 & - & - & - & - & - & 0.8 & - & $\cdots$ & - \\
\hline$\Delta \omega_{i}$ & 0.99 & - & 0.99 & 0.97 & 0.98 & 0.95 & 0.97 & & - & $\cdots$ & 0.99 \\
\hline$\Delta \omega_{k}$ & - & 0.95 & - & - & - & - & - & 0.99 & - & $\cdots$ & - \\
\hline$\Delta P_{k \min }, \mathrm{kW}$ & - & 4 & - & - & - & - & - & 5 & - & $\ldots$. & - \\
\hline$\Delta P_{k \max }, \mathrm{kW}$ & - & 10 & - & - & - & - & - & 25 & - & $\cdots$ & - \\
\hline$p_{1 i}, \mathrm{~kW}$ & 34 & & 7 & 34 & 56 & 14 & 8 & & - & $\cdots$ & 18 \\
\hline$p_{2 i}, \mathrm{~kW}$ & - & 12 & - & - & - & - & - & 25 & - & $\cdots$ & - \\
\hline$m_{P} / \sigma_{P}, \mathrm{~kW}$ & - & - & - & - & - & - & - & - & $12 / 3$ & $\cdots$ & - \\
\hline
\end{tabular}


The result of solving problem (10) are the sets $x_{i}=\left\{x_{1}, x_{2}, x_{3} \ldots x_{n}\right\}, x_{i}=0,1(i) \in Z$ and $y_{k}=\left\{y_{1}, y_{2}, y_{3} \ldots y_{m}\right\}, y_{k} \in(0-1)$, in accordance with which the controlled electric receivers are managed, including due to the shift of technological operations in time.

In Fig. 3 shows the load graphs of the groups of electric receivers and the total obtained based on the solution of the optimization problem of managing the demand of an active consumer (for a period of time with a power limit). Here $\Delta P_{1}=\sum_{i=1}^{n} p_{1 i}^{t} x_{i}, \Delta P_{2}=\sum_{k=1}^{m} p_{2 k}^{t} y_{k}-$ estimated decrease in the active power of disconnected electric receivers and with flexible performance control at a specified point in time, respectively. The power limit was assumed to be $P_{o p}=460 \mathrm{~kW}$, the safety factor $k_{t}=1,1$. The load curve sample is represented by 170 points in time from 8:00 to 18:00.

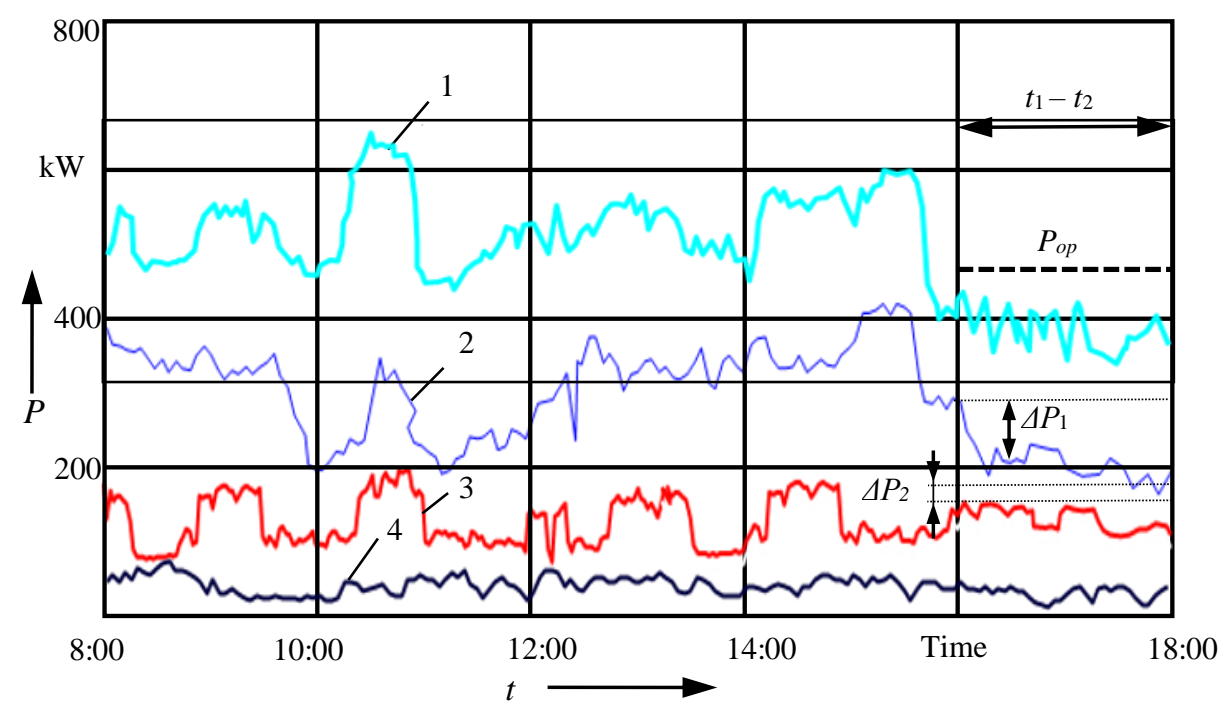

Fig. 3. Active power graphs. 1 - total graph taking into account power limitations; 2 - graph of disconnected electric receivers; 3 - graph of electric receivers with flexible power control; 4 - graph of uncontrolled and (or) non-disconnected electric receivers.

The indicated load schedules are calculated, including based on the measured power parameters of individual electric receivers, grouped according to given conditions, and uncontrolled (random stationary) in accordance with expression (2). Unsteady random inclusion of loads can be taken into account by adjusting the value of the safety factor.

The network diagram of the technological processes of the workshop under consideration is presented taking into account the adjustment of the active power load schedule: to limit the power, the network schedule was shifted in time within the allowable limits specified by the initial logical conditions.

\section{Discussion}

Based on the presented algorithm, a demand management method has been developed by active consumers in the normal mode of intelligent electric power systems, the hallmarks of which are: 
- analysis of power consumption data and operating modes is carried out on the basis of the use of modern technical means of measurement, control and switching of electric receivers (advanced metering infrastructure - AMI);

- the optimal load schedule is formed not on the basis of the predicted sets of power combinations of electric receivers, but by controlling the on-limit (shutdown) and smooth change of power of the controlled electric receivers in real time;

- in the model of power consumption, the load is divided into controlled (disconnected and with flexible power control) and uncontrolled, including random.

The presented results of the implementation of the considered approach to demand management by an active consumer using the example of one plant workshop allow us to talk about the possibility of solving a similar problem by software tools for a large enterprise as a whole with reference to the technological process for several connections to the electric power system.

If necessary, the presented expression (3) can be translated into minimizing the cost of electricity consumption by including a factor with the cost of electricity at each moment in time and (or) supplementing its own generation (accumulation) of power with a variable cost, which is the subject of further research by the authors.

\section{References}

1. E. Onur, S.Ugur, IEEE International Conference on Smart Energy Grid Engineering (SEGE) (2017). DOI: 10.1109/SEGE.2017.8052781

2. S.B. Surekha, T. Chandrashekhar, International Conference on Signal Processing, Communication, Power and Embedded System (SCOPES) (2016). DOI: 10.1109/SCOPES.2016.7955498

3. G. Gaurav, M. Nishtha, K. Rintu, K. Sandeep, IEEE International Conference on Smart Grid and Smart Cities (ICSGSC) (2017). DOI: 10.1109/ICSGSC.2017.8038581

4. G. Benysek, J. Bojarski, R. Smolenski, M. Jarnut, S. Werminski, IEEE Transactions on Smart Grid 9, 1055-1062 (2018). DOI: 10.1109/TSG.2016.2574891

5. Z. Huaguang, Li Yushuai, W. David, Z. Jianguo, IEEE Transactions on Industrial Informatics 13, 1-6 (2017). DOI: 10.1109/TII.2017.2714199

6. C.M. Lin, M.T. Chen, IEEE 3rd International Future Energy Electronics Conference and ECCE Asia (IFEEC 2017-ECCE Asia) (2017) DOI: 10.1109/IFEEC.2017.7992392

7. K. Jhala, B. Natarajan, A. Pahwa, IEEE Transactions on Smart Grid 10.3, 2809-2819 (2018). DOI: 10.1109/TSG.2018.2810819

8. E.A. Tretyakov, Conf. Ser.: Materials Science and Engineering 643 (2019). DOI: 10.1088/1757-899X/643/1/012005

9. Sang Ju Lee, et al., IEEE 18th International Conference on Advanced Communication Technology (ICACT) (2016). DOI: 10.1109/ICACT.2016.7423508

10. M. Furukakoi, et al., IEEE 17th International Conference on Control, Automation and Systems (ICCAS) (2017). DOI: 10.23919/ICCAS.2017.8204470

11. N. HSVS Kumar, S. Dipti, IEEE International Conference on Power Electronics, Drives and Energy Systems (PEDES) (2016). DOI: 10.1109/PEDES.2016.7914490

12. S.P. Anjana, T.S. Angel, International Conference on Technological Advancements in Power and Energy (TAP Energy) (2017). DOI:10.1109/TAPENERGY.2017.8397265

13. E.A. Tretyakov, MATEC Web of Conferences 239 (2018). DOI: 10.1051/matecconf/201823901010. 
14. A. Jordehi, Rezaee, Renewable and Sustainable Energy Reviews 103(C), 308-319 (2019). DOI: 10.1016/j.rser.2018.12.054

15. H. Palásthy, J. Majherová, I. Černák, International Conference on E-Learning and ETechnologies in Education (ICEEE) (2012). DOI: 10.1109/ICeLeTE.2012.6333389 